\title{
Uranium Sorption Using Lewatit MonoPlus M500 from Sulphate Media
}

\author{
Sally Sayed Muhammad \\ Department of Uranium Ores Processing, Production Sector, Nuclear Materials Authority, Cairo, Egypt \\ Email address: \\ sally_rose79@hotmail.com

\section{To cite this article:} \\ Sally Sayed Muhammad. Uranium Sorption Using Lewatit MonoPlus M500 from Sulphate Media. Science Journal of Chemistry. \\ Vol. 8, No. 1, 2020, pp. 7-19. doi: 10.11648/j.sjc.20200801.12
}

Received: September 18, 2019; Accepted: December 9, 2019; Published: March 10, 2020

\begin{abstract}
The present work has focused on the uptake behavior of uranium (VI) from sulfuric acid media by using Lewatit MonoPlus M500 resin. The influence of parameters, namely pH, U (VI) initial concentration, contact time and temperature were investigated. The optimum conditions were explicated via the sorption kinetics, the isotherm models and the thermodynamic data to determine the behavior of the uranium adsorption. The studied resin is an efficient sorbent for $\mathrm{U}(\mathrm{VI})$ ions with maximum sorption capacity $\mathrm{q}_{\max } 181.82 \mathrm{mg} \mathrm{g}^{-1}$ and agreed with both the pseudo-second order kinetic model and Langmuir isotherm. Thermodynamic characteristics showed that the process was spontaneous $\left(\Delta \mathrm{G}^{\circ}<0\right)$ and exothermic $\left(\Delta \mathrm{H}^{\circ}\right.$ $<0$ ) in nature. Finally, by application of the results to increase the uranium assay and purity in the working impure uranium concentrate which produced at Gattar pilot plant, Egypt. The assay increase from about $36 \%$ up to $71 \%$, while the purity up to $94 \%$.
\end{abstract}

Keywords: Uranium, Sorption, Sulphuric Media, Lewatit Mono Plus M500

\section{Introduction}

Ion exchange resins are the most important and versatile mediums used in the treatment of aqueous solutions. Constantly growing demands on water quality requires increasing sophistication of both the ion exchange resins and the related application technologies. With Lewatit MonoPlus, a new range of ion exchange resins, these systems are taken to a new level. In the early 1980's Bayer was the first company to develop a process for producing monodispersive ion exchange resins. There are different types of monodispersive ion exchangers, such as: (1) Cation exchanger: a. strongly acidic, gel type, e.g. MonoPlus S108, b. strongly acidic, macroporous, e.g. Lewatit MonoPlus ASP 112 [1], and K-14chS (TOKEM-145-9.5) resin [2]. c. slightly acidic, macroporous, e.g. Lewatit CNP 80. (2) Anion exchanger: a. strongly alkaline, gel type, e.g. MonoPlus M 500. b. strongly basic, macroporous, e.g. MonoPlus 800 [1], and A-14chS (TOKEM-845-8) [2]. c. weakly basic, macroporous, e.g. Lewatit ${ }^{\circledR}$ MonoPlus MP 64 [3], and Lewatit MP 62 WS. (3) Acrylic exchanger, e.g. Lewatit VPOC 1071. (4) Inert resin, e.g. Lewatit IN 42 [1].

Lewatit MonoPlus ion exchange resins have a considerable number of advantages over heterodisperse types. The bead size diameter for Lewatit MonoPlus lies between 0.55 and $0.75 \mathrm{~mm}$, depending on the type. This type of resins is characterized by monodispersity higher than $90 \%$ (more than $90 \%$ of all beads are within $0.05 \mathrm{~mm}$ of the given bead diameter); therefore the above-mentioned monodispersive form of resins gives high efficiency, higher stability and extremely robust results in their long lifetimes. In practice, this advantage leads to higher permitted differential pressures, allowing greater resin bed depth and higher velocities. Moreover, their good kinetic properties cause reduction of required bed depth and ion leakage and permit shorter cycle times. The better kinetic properties, the better exchange behavior resulting in lower regenerate and rinse water demand. Increase of regeneration efficiency and unit capacity (total capacity is improved by about $10 \%$ compared to the heterodisperse one) as well as decreases in the amount of resin required (smaller column) and operating costs are the results of their high operating capacity [4].

From the literature, Lewatit MonoPlus resins are widely applied in a range of industries such as purification of organic liquids as the removal of glycerin from biodiesel, recovery of reusable materials (chromium, molybdenum, 
copper, gold), uranium extraction, separation of the rare earths, wastewater treatment, waste air purification and soil purification.

Lewatit MonoPlus M 500 and Lewatit FO36 are used in separation of $\mathrm{As}(\mathrm{III})$ and $\mathrm{As}(\mathrm{V})$ species from natural and drinking water [5]. Lewatit MonoPlus M 500, Lewatit MonoPlus M 600 and Lewatit MonoPlus MP 500 used in sorption of heavy metal ions- $\mathrm{Cu}(\mathrm{II}), \mathrm{Co}(\mathrm{II}), \mathrm{Ni}(\mathrm{II})$ and $\mathrm{Fe}(\mathrm{III}$ ) - from aqueous solutions containing iminodisuccinic acid (IDS) or EDTA [6]. Lewatit MonoPlus MP 600 has been studied for the simultaneous sorption recovery of $\mathrm{Pt}(\mathrm{IV})$, $\mathrm{Pd}(\mathrm{II})$ and $\mathrm{Rh}$ (III) present in chloride solution collected from the leaching platinum group metal-containing spent automotive catalyst [7]. Lewatit FO36 can be successfully used for the adsorption of $\mathrm{Cr}$ (VI) from aqueous solutions using the batch method [8]. A chelating resin of a new generation with the bi's-picolylamine functional groups, namely Lewatit MonoPlus TP-220 was applied in selected noble metal recovery such as palladium(II), platinum(IV), gold(III) and base metals such as $\mathrm{Cu}(\mathrm{II}), \mathrm{Co}(\mathrm{II}), \mathrm{Ni}(\mathrm{II})$ and $\mathrm{Zn}$ (II) [9]. Sorption recovery of palladium(II) present in chloride and chloride-nitrate $(\mathrm{V})$ solutions can be achieved by applying the commercial strongly basic anion exchanger Lewatit MonoPlus SR-7 [10].

Uranium was extracted from carbonate leach liquor using Lewatit Mono plus M500 as anion exchange resin with $77 \%$ extraction efficiency. Bell curve was achieved from the elution process with $89.5 \%$ elution efficiency [11]. Also, the adsorption behavior of Lewatit mono plus M500 resin was studied by batch experiments to determine the optimum conditions for uranium removal rare earths sulfate liquor contaminated with traces of uranium as radioactive contaminates [12].

This paper describes the applicability of Lewatit MonoPlus M 500 in uranium(VI) removal from the sulphate solution attained from Gattar pilot plant, Nuclear Materials Authority, Egypt. Kinetic and equilibrium studies of the sorption process and regeneration and reuse of this resin were considered.

\section{Experimental}

\subsection{Reagents and Solutions}

All reagents used were of analytical reagent grade. The standard uranium sulphate solution was prepared by dissolving uranyl sulphate trihydrate $\mathrm{UO}_{2} \mathrm{SO}_{4} \cdot 3 \mathrm{H}_{2} \mathrm{O}$ obtained from Ibilabs, Florida, USA. The working Lewatit MonoPlus M500 resin was purchased from Lanxess (Germany). The physicochemical properties and brief specifications of this resin are presented in Table 1. Prior to use, resin pretreattment was carried out by washing with distilled water, followed by contacting with $0.5 \mathrm{M}$ sulfuric acid for several times to remove organic and inorganic impurities from its synthesis and was finally aired-dried.

Table 1. Characteristics of the Lewatit MonoPlus M500 ion exchange resin。

\begin{tabular}{|c|c|c|}
\hline \multicolumn{2}{|c|}{ Resin type } & Strongly basic anion exchange resin, type 1 \\
\hline \multicolumn{2}{|l|}{ Matrix } & Crosslinked styrene-divinylbenzene (gel) \\
\hline \multicolumn{2}{|l|}{ Structure } & gel type beads \\
\hline \multirow{2}{*}{\multicolumn{2}{|c|}{ Ionic form as shipped }} & $\mathrm{Cl}^{-}$ \\
\hline & & Quaternary ammonium \\
\hline \multicolumn{2}{|c|}{ Functional group } & $\mathrm{H}_{2}-$ \\
\hline \multicolumn{2}{|c|}{ Appearance } & yellow, translucent \\
\hline \multicolumn{2}{|c|}{ Operating temperature } & $\max .70^{\circ} \mathrm{C}$ \\
\hline \multicolumn{2}{|c|}{ Operating pH-range } & $0-12$ \\
\hline \multicolumn{2}{|c|}{ Mean bead size } & $0.62(+/-0.05)$ \\
\hline \multirow{3}{*}{$\begin{array}{l}\text { Stability } \\
\text { Regeneran }\end{array}$} & $\mathrm{pH}$ range & $0-14$ \\
\hline & Temperature range & $-20^{\circ} \mathrm{C}-40^{\circ} \mathrm{C}$ \\
\hline & & $\mathrm{NaOH}$ \\
\hline
\end{tabular}

\subsection{Apparatus and Analytical Procedure}

The quantitative analysis of uranium was achieved spectrophotometrically by UV single beam spectrophotometer model SP-8001", Metretech Inc., version 1.02 using Arsenazo III method [13] and curtained by an oxidimetric titration against ammonium metavanadate method using N-phenyl anthranilic acid indicator (SigmaAldrich) [14]. All experiments were carried out three times and only the average values were reported.

Environmental scanning electron microscope (ESEM), Philips XL30, Nuclear Material Authority (NMA), Egypt, was used in order to obtain information about Lewatit MonoPlus M500 surface morphology also, the purity of final precipitate of uranium qualitatively. The FTIR spectroscopy was employed to confirm the interactions between Lewatit MonoPlus M500 resin and uranium ions using 4100 JascoJapan infrared spectrophotometer, Cairo University.

\subsection{Sorption Experiments}

In order to organize, establish and understand an adequate design model for the removal of uranium from aqueous media, isotherms, kinetics, thermodynamic and desorption studies are essential basic prerequisites. These studies were carried out using the batch experiments method.

Sorption experiments were conducted using a batch technique to determine the optimum adsorption conditions, including $\mathrm{pH}$, contact time, initial metal ion concentration and temperature, so batch experiments were carried out by contact of $0.1 \mathrm{~g}$ of Lewatit MonoPlus M500 with $10 \mathrm{ml}$ of 
uranium sulfate synthetic solution (of $200 \mathrm{mg} / \mathrm{L}$ initial uranium concentration) in a stopped conical flasks and placed on mechanical shaker at room temperature. The adsorption efficiency of uranium by the resin under discussion was estimated by means of the recovery degree $(\mathrm{R}, \%)$, which is the difference between its equilibrium and initial concentrations as the following equation:

$$
\mathrm{R}=\left(\mathrm{C}_{\mathrm{o}}-\mathrm{C}_{\mathrm{e}} / \mathrm{C}_{\mathrm{o}}\right) \times 100 \%
$$

and the equilibrium sorption capacity is expressed as

$$
\mathrm{q}_{\mathrm{e}}=\left(\mathrm{C}_{\mathrm{o}}-\mathrm{C}_{\mathrm{e}}\right) \times \mathrm{V} / \mathrm{M}
$$

Where $\mathrm{C}_{\mathrm{o}}$ and $\mathrm{C}_{\mathrm{e}}$ are the original and the equilibrium concentrations of uranium $(\mathrm{mg} / \mathrm{L})$, respectively, $\mathrm{V}$ is the volume of the aqueous phase (L), and $\mathrm{M}$ is the weight of the resin used $(\mathrm{g})$.

For elution process, the loaded uranium was eluted from the Lewatit MonoPlus M500, through applying a number of eluting agents with different concentrations.

\section{Results and Discussion}

\subsection{Effect of $p H$}

The $\mathrm{pH}$ of the aqueous solution plays an important role in the whole adsorption process and particularly on the adsorption capacity, influencing the surface charge of the adsorbent, the degree of ionization of the materials, and the dissociation of functional groups such as, carboxyl, hydroxyl and amino on the active sites of the adsorbent [15]. It can also influence the aqueous chemistry of uranium [16]. The mobility of the other ions in the medium is affected by concentration of $\mathrm{H}^{+}$ions. Moreover, it also affects interest and capacity of adsorbents for target species. There is always a competition between $\mathrm{H}^{+}$ions and target species depending on $\mathrm{pH}$ in the medium [17]. Especially, if there are polyphonic or polycationic species in their solution, interactions are fairly affected by the $\mathrm{pH}$ of the medium.

The effect of initial solution $\mathrm{pH}$ was investigated by preparing a series solution having a different $\mathrm{pH}$ within the range 0.5 to 2.8 , adjusted by using either $0.5 \mathrm{M} \mathrm{H}_{2} \mathrm{SO}_{4}$ or $0.5 \mathrm{M} \mathrm{NaOH}$. As a result of this experiment, it was observed that the uranium adsorption efficiency, increased from $37.2 \%$ at $\mathrm{pH} 0.5$ to a maximum value of $90.6 \%$ at $\mathrm{pH} 1.8$ and then declines slowly from $90.6 \%$ to $82.5 \%$ as shown in Figure 1 . The bivalent $\left[\mathrm{UO}_{2}\left(\mathrm{SO}_{4}\right)_{2}\right]^{2-}$ and in particular the tetravalent uranium sulfate complexes $\left[\mathrm{UO}_{2}\left(\mathrm{SO}_{4}\right)_{3}\right]^{4-}$ at lower $\mathrm{pH}$ were found to have a high affinity for the anionic exchange resins $[18,19]$.

So, $\mathrm{pH} 1.8$ of the sample was selected for further experiments. In the adsorption cycle or step, the uranium anionic complexes are adsorbed on the resin and their interaction may be represented as follows, where $\mathrm{R}$ represents the fixed ion-exchange sites of the resin, and $\mathrm{X}^{-}$ equals sulfate anions.

$$
\left[\mathrm{UO}_{2}\left(\mathrm{SO}_{4}\right)_{2}\right]_{\text {aq. }}^{2-}+2 \mathrm{RX} \leftrightarrow \mathrm{R}_{2}\left[\mathrm{UO}_{2}\left(\mathrm{SO}_{4}\right)_{2}\right]+2 \mathrm{X}_{\text {aq }}^{-}
$$

$$
\left[\mathrm{UO}_{2}\left(\mathrm{SO}_{4}\right)_{3}\right]_{\text {aq. }}^{4-}+4 \mathrm{RX} \leftrightarrow \mathrm{R}_{4}\left[\mathrm{UO}_{2}\left(\mathrm{SO}_{4}\right)_{3}\right]+4 \mathrm{X}^{-}{ }_{\text {aq. }}
$$

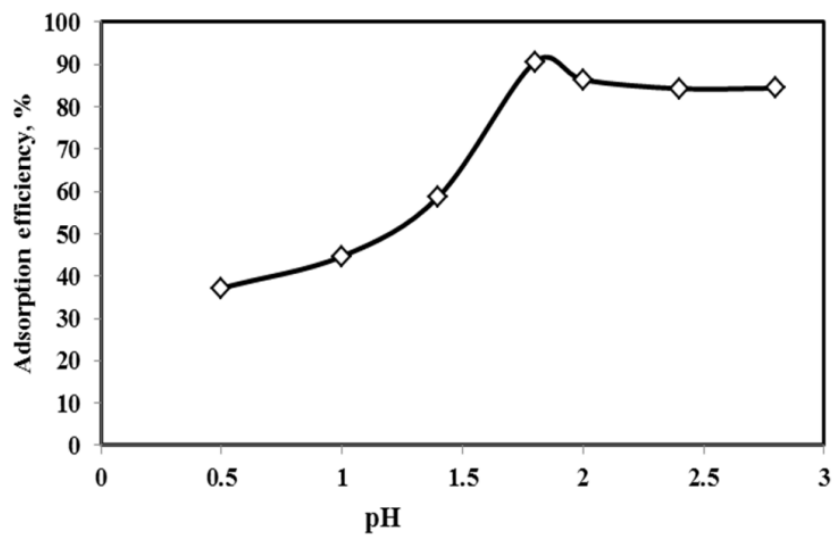

Figure 1. $p H$ dependence of the uranium adsorption efficiency.

\subsection{Effect of Resin/Liquid (Sulphate Solution) Ratio (R/L)}

A series of $(\mathrm{R} / \mathrm{L})$ ratios was performed from $1 / 15$ to $1 / 70$ under constant uranium concentration, at room temperature for $30 \mathrm{~min}$ time and $\mathrm{pH}$ 1.8. The obtained data are plotted in Figure 2. It was observed that the adsorption efficiency, increased with increasing the pregnant feed solution from $1 / 15$ to $1 / 50$ for the resin, more increase in the pregnant feed solution gave a slight increase in uranium adsorption efficiency, so the ratio $1 / 50$ was recommended the optimum ratio.

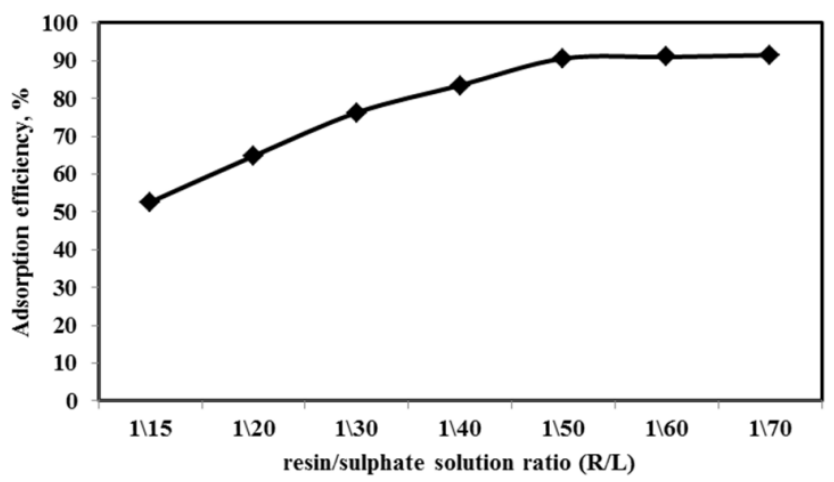

Figure 2. Effect of resin/ liquid (sulphate solution) ratio on uranium adsorption.

\subsection{Effect of Uranium Initial Concentration}

The initial concentration of uranium was studied by contacting $0.1 \mathrm{~g}$ of Lewatit MonoPlus M500 with $10 \mathrm{ml}$ of uranium sulfate synthetic solution of different initial concentration of uranium ranging from $10 \mathrm{mg} / \mathrm{L}$ to 1000 $\mathrm{mg} / \mathrm{L}$ for $30 \mathrm{~min} ., \mathrm{pH} 1.8$, and $200 \mathrm{rpm}$ at room temperature.

From Figure 3, the uranium ions sorption increased with the initial concentrations of metal ions, increasing at the beginning and then reached to surface saturation at high concentrations. This indicated that, at lower initial concentrations of uranium ions, the sorption sites on the adsorbent were sufficient for the metal ions, the sorption relied on the amount of metal ions transported from the 
bulk solution to the surfaces of the sorbents. However, at higher initial concentrations of $\mathrm{UO}_{2}{ }^{2+}$ ions, the adsorption sites on the surfaces of the sorbents reached to saturation, and the sorption of $\mathrm{UO}_{2}{ }^{2+}$ ions achieved equilibrium [20, 21]. This could be due to a higher probability of collision between uranium ions and the adsorbent surface and a better driving force, which lessens the mass transfer resistance, the sorption sites on the surfaces of the sorbent reached to saturation, and the sorption of uranium ions achieved equilibrium $[22,23]$.

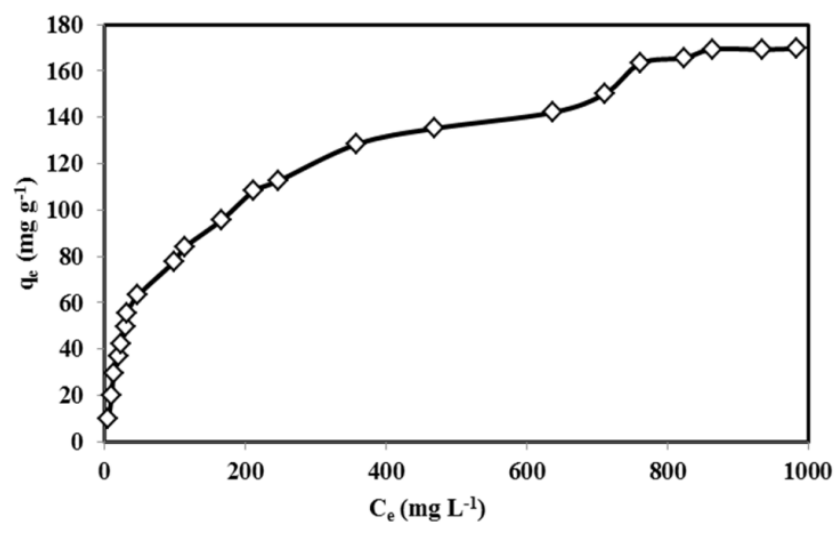

Figure 3. Effect of uranium initial concentration on the sorption capacity.

\section{Sorption isotherms studies}

The metal ions can be adsorbed from their solutions onto the surface of solid sorbent by several mechanisms. To investigate the best fitting isotherm model, the sorption experiments were conducted at the previously found optimum conditions.

Sorption isotherm studies are extensively used to provide information about the amount of adsorbed ion by a certain adsorbent and about the interaction between the adsorbents and adsorbate [24].

The Sorption equilibrium data have been analyzed using various isotherm models, such as the Langmuir, Freundlich and Dubinin-Radushkevich (D-R) models [23]. Non-linear regression method was applied to the results in order to see the harmony between experimental results and theoretical models. Though the fit of experimental data by a given equation does not necessarily means that the mechanisms associated with the model are verified, this may help in interpreting the adsorption mechanism.

i. Langmuir Isotherm Model

The Langmuir [22] isotherm is based on the following assumptions: (a) adsorbents are chemically adsorbed at a fixed number of well-defined sites; (b) a monolayer of the adsorbent is formed over the surface of the adsorbent when it gets saturated; (c) each site can hold only one adsorbate species; (d) all sites are energetically equivalent; (e) interactions between the adsorbate species do not exist.

The Langmuir isotherm equation is depicted by Eq.(3):

$$
\mathrm{C}_{\mathrm{e}} / \mathrm{q}_{\mathrm{e}}=\left(1 / \mathrm{q}_{\max }\right) \mathrm{C}_{\mathrm{e}}+\left(1 / b \mathrm{q}_{\max }\right)
$$

where $\mathrm{q}_{\mathrm{e}}$ is the amount of adsorbent adsorbed at the equilibrium ( $\left.\mathrm{mg} \mathrm{g}^{-1}\right), \mathrm{C}_{\mathrm{e}}$ is the supernatant adsorbate concentration at the equilibrium $\left(\mathrm{mg} \mathrm{L}^{-1}\right), \mathrm{b}$ is the Langmuir equilibrium constant $\left(\mathrm{L} \mathrm{mg}^{-1}\right)$, and $\mathrm{q}_{\max }$ is the maximum adsorption capacity of the adsorbent $\left(\mathrm{mg} \mathrm{g}^{-1}\right)$ assuming a monolayer of adsorbate uptake by the adsorbent. So, the adsorption increases with concentration until active center on the surface is fulled by analyte ions. The adsorbed amount reaches a plateau and equilibrium with increasing concentration.

Experimental results are plotted as shown in Figure 4 using the linearized Langmuir equation, and the parameters of the model are summarized in Table 2.

For further analysis of the adsorption process, a dimensionless constant (or the separation factor) $\left(R_{L}\right)$, which reflects the essential characteristic of Langmuir model, can be obtained from the constant $b$ from Eq.(4):

$$
\mathrm{R}_{\mathrm{L}}=1 /\left(1+\mathrm{b} \mathrm{C}_{\mathrm{o}}\right)
$$

where $b\left(\mathrm{~L} \mathrm{mg}^{-1}\right)$ refers to the Langmuir constant and $\mathrm{C}_{\mathrm{o}}$ is denoted to the adsorbate initial concentration $\left(\mathrm{mg} \mathrm{l}^{-1}\right)$. In this context, lower $R_{L}$ value (from 0.92 to 0.09 ) reflects that adsorption is more favorable. In a deeper explanation, $\mathrm{R}_{\mathrm{L}}$ value indicates the adsorption nature to be either unfavorable $\left(\mathrm{R}_{\mathrm{L}}>1\right)$, linear $\left(\mathrm{R}_{\mathrm{L}}=1\right)$, favorable $\left(0<\mathrm{R}_{\mathrm{L}}<1\right)$ or irreversible $\left(\mathrm{R}_{\mathrm{L}}=0\right)[23,25]$.

From this research work, the maximum monolayer coverage capacity $\left(\mathrm{q}_{\max }\right)$ from the Langmuir isotherm model was determined to be $181.82 \mathrm{mg} \mathrm{g}^{-1}, \mathrm{~b}$ (Langmuir isotherm constant) is $0.0091 \mathrm{~L} \mathrm{mg}^{-1}, \mathrm{R}_{\mathrm{L}}$ (the separation factor) is from 0.92 to 0.09 indicating that the equilibrium sorption was favorable and the $\mathrm{R}^{2}$ value is 0.989 proving that the sorption data fitted well to Langmuir Isotherm model.

ii. Freundlich Isotherm Model

Freundlich [26] isotherm model is an exponential equation, and assumes that the concentration of adsorbate on the adsorbent surface increases as the adsorbate concentration increases. Theoretically, using this expression, an infinite amount of adsorption will occur. Similarly, the model assumes that the adsorption could occur via multiple layers instead of a single layer. The equation has a wide application in heterogeneous systems. Eq.(5) shows the Freundlich isotherm model;

$$
\log \mathrm{q}_{\mathrm{e}}=\log \mathrm{k}_{\mathrm{f}}-1 / \mathrm{n} \log \mathrm{C}_{\mathrm{e}}
$$

where $\mathrm{k}_{\mathrm{f}}$ (the Freundlich isotherm constant) is an approximate indicator of adsorption capacity, and $\mathrm{n}$ is the Freundlich exponent (dimensionless) is the heterogeneity factor [23] and it is a function of the strength of adsorption in the adsorption process [27]. If $n=1$ then the partition between the two phases are independent of the concentration. If a value of $1 / \mathrm{n}$ is below one it indicates a normal adsorption. On the other hand, $1 / \mathrm{n}$ being above one indicates cooperative adsorption [28]. It is accepted that heterogeneity of surface is increased if $n$ value approaches to 1 . From the data in Table 2 , that a value of $1 / n=0.46$ while $n=2.19$ indicating that the sorption process is favorable and the $\mathrm{R}^{2}$ 
value is 0.932 .

iii. Dubinin-Radushkevich (D-R) Isotherm Model

Dubinin-Radushkevich isotherm is generally applied to express the adsorption mechanism with a Gaussian energy distribution onto a heterogeneous surface $[29,30]$. The linearized form of the D-R equation is given by Eq.(6):

$$
\ln \mathrm{q}_{\mathrm{e}}=\ln \mathrm{q}_{\mathrm{D}}-\mathrm{K}_{\mathrm{DR}} \varepsilon^{2}
$$

where $\mathrm{q}_{\mathrm{D}}$ is the theoretical isotherm saturation capacity, $\mathrm{K}_{\mathrm{DR}}$ is related to the mean free adsorption energy per molecule of adsorbate and $\varepsilon\left(\mathrm{kJ}^{2} \mathrm{~mol}^{-2}\right)$ is the Polanyi potential and it is expressed as follows Eq.(7):

$$
\varepsilon=\mathrm{RT} \ln \left(1+1 / \mathrm{C}_{\mathrm{e}}\right)
$$

where $\mathrm{R}$ is the universal gas constant $\left(8.314 \times 10^{-3} \mathrm{~kJ} \mathrm{~mol}^{-1}\right.$ $\mathrm{K}^{-1}$ ) and $\mathrm{T}$ is the absolute temperature, $\mathrm{K}$.

The approach was usually applied to distinguish the physical and chemical adsorption of metal ions with its mean free energy, $E_{D R}$ per molecule of adsorbate (for removing a molecule from its location in the sorption space to the infinity) can be computed by the relationship $[31,32]$ :

$$
\mathrm{E}_{\mathrm{DR}}=(2 \mathrm{~K})^{-1 / 2}
$$

It is commonly accepted that physical adsorption corresponds to mean adsorption energy below $8 \mathrm{~kJ} \mathrm{~mol}^{-1}$ while chemical adsorption requires mean adsorption energy greater than 8-16 $\mathrm{kJ} \mathrm{mol}^{-1}[23,33]$. One of the unique features of the Dubinin-Radushkevich (DRK) isotherm model lies on the fact that it is temperature-dependent, which, when adsorption data at different temperatures are plotted as a function of the logarithm of the amount adsorbed $\left(\operatorname{Ln} \mathrm{q}_{\mathrm{e}}\right)$ vs $\varepsilon^{2}$ the square of potential energy, all suitable data will lie on the same curve, named as the characteristic curve [23].

In the present work, the experimental adsorption data were fitted based on the aforementioned isotherm models. All parameters were obtained from the slopes and intercepts of the fitted straight lines of the three isotherm plots are shown in Figure 4 and are summarized in Table 2. Based on Table 2, the correlation coefficients $\left(\mathrm{R}^{2}\right)$ of the linear form of the Langmuir model were nearly closer to $\approx 1.0$ than the values obtained with the Freundlich model and a maximum adsorption capacity $\left(181.82 \mathrm{mg}^{-1}\right)$ close to that experimentally determined $\left(\approx 169 \mathrm{mg} \mathrm{g}^{-1}\right)$. This was expectable based on the shape of sorption isotherms: the saturation plateau is consistent with the asymptotic trend associated with the Langmuir equation, while the Freundlich equation means an exponential trend. Calculated $\mathrm{R}_{\mathrm{L}}$ value (from 0.92 to 0.09 ) was less than 1 while the value of $n$ was greater than 1 reflects that adsorption process is more favorable. This suggests that uranium occurs through monolayer sorption onto a surface, with a finite number of identified sites, which are homogeneously distributed over the adsorbent surface.

The values of $\mathrm{K}_{\mathrm{F}}, 1 / \mathrm{n}$ and $\mathrm{R}^{2}$ in the Freundlich model (Figure 4) are reported in Table 2. The value of $1 / \mathrm{n}$ is less than 1; whatever the concentration and the temperature: this means that the sorption is a favorable process over the entire concentration range [23, 34]; however, the correlation coefficient is lower than in the case of the Langmuir equation.

Meanwhile, from the Dubinnin-Radushkevich (D-R) isotherm, the plot of $\ln \mathrm{q}_{\mathrm{e}}$ versus $\varepsilon^{2}$ gives a straight line with the slope $K$ and the intercept $\ln \mathrm{q}_{\mathrm{D}}$ shown in Figure 4. The parameters of the model are reported in Table 2. The calculated value of the mean adsorption energy $\left(\mathrm{E}_{\mathrm{DR}}\right)$ is 1.6 $\mathrm{kJ} \mathrm{mol}^{-1}$ which is below $8 \mathrm{~kJ} \mathrm{~mol}^{-1}$, suggesting that the uptake of uranyl ions was driven by physisorption process based on van der waals forces.
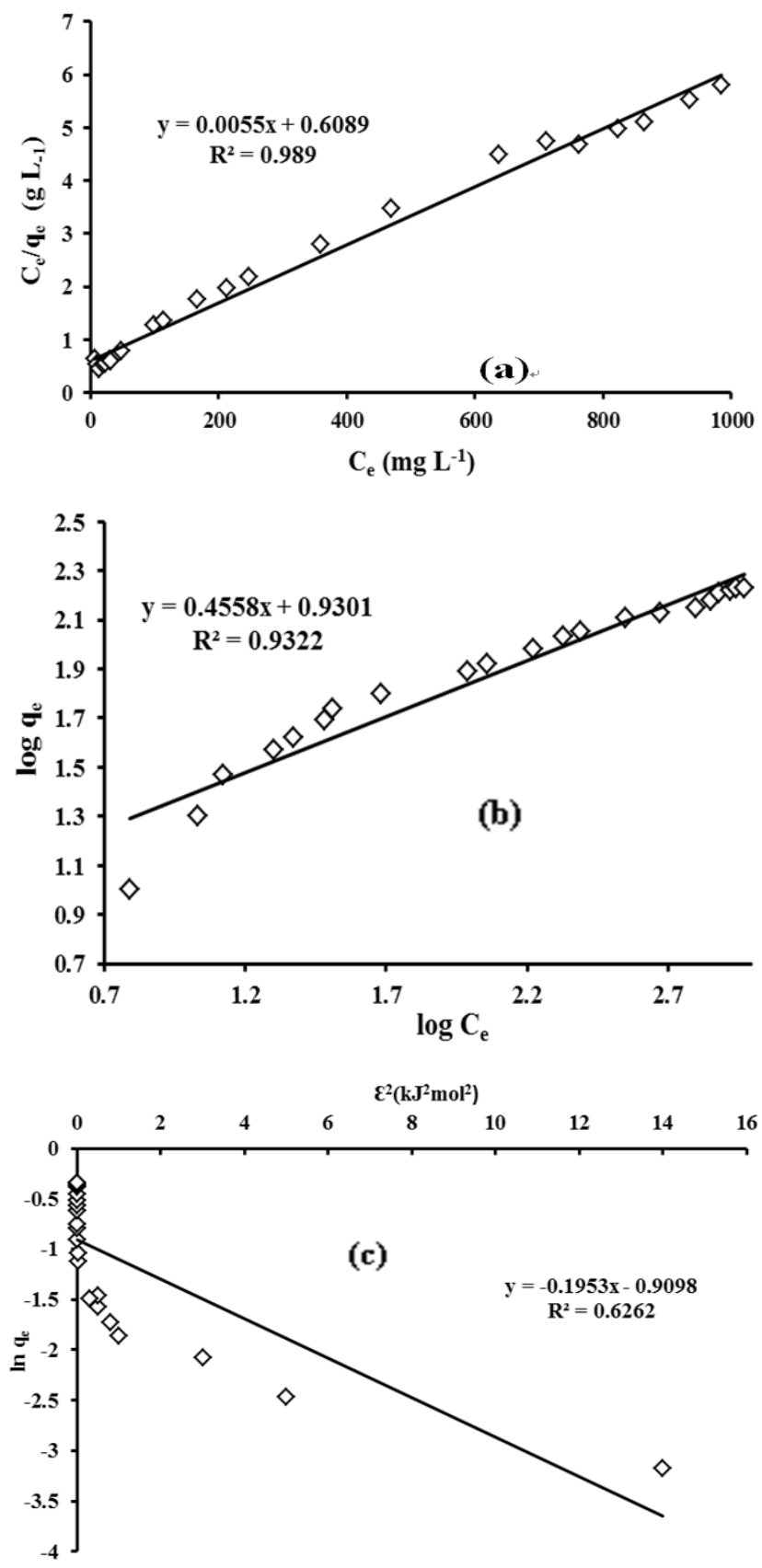

Figure 4. Isotherms models: (a) Langmuir, (b) Freundlich and (c) D-R for U(VI) sorption onto Lewatit MonoPlus M500. 
Table 2. Isotherm constants for U(VI) ions sorption.

\begin{tabular}{llll}
\hline Model & Parameters & & \\
\hline \multirow{2}{*}{ Langmuir } & $\mathrm{q}_{\max }$ & $\mathrm{b}$ & $\mathrm{R}^{2}$ \\
& $181.82 \mathrm{mg} \mathrm{g}^{-1}$ & $0.0091 \mathrm{~L} \mathrm{mg}^{-1}$ & 0.989 \\
Freundlich & $\mathrm{n}$ & $\mathrm{k}_{\mathrm{f}}$ & $\mathrm{R}^{2}$ \\
& 2.19 & $8.51 \mathrm{mg} \mathrm{g}^{-1}$ & 0.932 \\
Dubinin- & $\mathrm{q}_{\max , \mathrm{D}-\mathrm{R}}$ & $\mathrm{E}_{\mathrm{DR}}$ & $\mathrm{R}^{2}$ \\
Raduskevich & $95.83 \mathrm{mg} \mathrm{g}^{-1}$ & $1.6 \mathrm{~kJ} \mathrm{~mol}^{-1}$ & 0.626 \\
\hline
\end{tabular}

A comparison between the adsorption capacity of Lewatit MonoPlus M500 resin and some other adsorbents is provided in Table 3. Since these experiments were not systematically obtained under similar experimental conditions, the strict comparison of absolute values is not easy; this simply gives an overview of the potential of the present sorbent against other materials.

Table 3. Comparison between the adsorption capacity of U(VI) on various adsorbents.

\begin{tabular}{lll}
\hline Adsorbent & $\begin{array}{l}\mathbf{U}(\mathbf{V I}) \text { sorption } \\
\text { capacity } \mathbf{q}_{\max }\left(\mathbf{m g ~ g}^{-\mathbf{1}}\right)\end{array}$ & References \\
\hline Amberlite IR-910 & 64.27 & {$[35]$} \\
Ambersep 920U SO & 58 & {$[36]$} \\
Amberjet 1200 H & 133 & {$[37]$} \\
Lewatit TP260 & 6 & {$[38]$} \\
Lewatit MonoPlus M500 resin & 181.82 & Present work \\
\hline
\end{tabular}

\subsection{Effect of Equilibration Time and Sorption Kinetic Studies}

The effect of the equilibrium time on the adsorption of $\mathrm{UO}_{2}{ }^{2+}$ ions was investigated from 0 to $90 \mathrm{~min}$, while other factors were fixed at $0.1 \mathrm{~g}$ of Lewatit MonoPlus M500 in 50 $\mathrm{ml} ; 200 \mathrm{mg} \mathrm{U} \mathrm{l}^{-1}$ were agitated at $200 \mathrm{rpm}$ at $25 \pm 1^{\circ} \mathrm{C}$.

Figure 5 shows a plot of the sorption capacity $\left(\mathrm{q}_{\mathrm{t}}, \mathrm{mg} \mathrm{U} \mathrm{\textrm {g } ^ { - }}\right.$ $\left.{ }^{1}\right)$ versus time $(\mathrm{t})$, the plot reveals that the kinetics of $\mathrm{UO}_{2}{ }^{2+}$ ions adsorption mainly consists of two stages: an initial rapid stage related to the instantaneous external surface adsorption of metal ions, that takes place for the first $30 \mathrm{~min}$ of contact and represents more than $90 \%$ of the total amount adsorbed, indicate that the $\mathrm{UO}_{2}{ }^{2+}$ ions adsorption process proceeded fast and reached saturation levels gradually due to the strong affinity of the uranium ions for Lewatit MonoPlus M500 resin (correlated to both the affinity of these reactive groups for uranyl ions and to the increased number of reactive groups). The second stage in the process corresponds to a slow phenomenon limited by the strong decrease in the availability of sorption sites (most of them being occupied; this corresponds to the approach to saturation). Based on these results a contact time of about $30 \mathrm{~min}$ is sufficient to achieve the equilibrium.

Kinetic studies

The study of adsorption kinetics is important in the treatment of aqueous effluents because it provides valuable pieces of information on the reaction pathways and the mechanism of adsorption reactions. Many kinetic models were developed to evaluate the intrinsic kinetic adsorption constants such as the pseudo-first order rate equation (PFORE), the pseudo-second order rate equation (PSORE) and the resistance to intraparticle diffusion (RIDE).

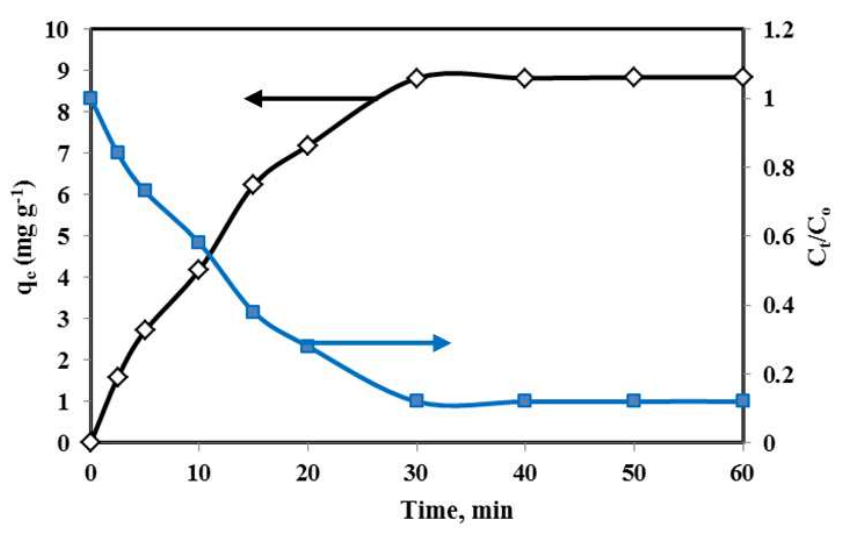

Figure 5. Effect of time on the adsorption of U(VI) ions.

\section{i. Pseudo-first-order rate equation (PFORE)}

The pseudo-first order of Lagergren assumes that the rate of change of solute uptake with time is directly proportional to the difference in saturation concentration and the amount of solid uptake to time. The kinetic was expressed as in the following Eq.(9) [25]:

$$
\log \left(\mathrm{q}_{\mathrm{e}}-\mathrm{q}_{\mathrm{t}}\right)=\log \mathrm{q}_{\mathrm{e}}-\left(\mathrm{k}_{1} / 2.303\right) \mathrm{t}
$$

where $\mathrm{q}_{\mathrm{e}}$ and $\mathrm{q}_{\mathrm{t}}\left(\mathrm{mg} \mathrm{g}^{-1}\right)$ are the adsorption capacities at equilibrium and time $\mathrm{t}(\mathrm{min})$, respectively. $\mathrm{k}_{1}\left(\mathrm{~min}^{-1}\right)$ is the rate constant of PFORE. The constants can be determined experimentally by plotting of $\log \left(\mathrm{q}_{\mathrm{e}}-\mathrm{q}_{\mathrm{t}}\right)$ against $\mathrm{t}$.

ii. Pseudo-second-order rate equation (PSORE)

The model $[20,39,40]$ is based on the assumption that the adsorption follows second order chemisorptions and predicts the behavior over the whole range of concentration and is in agreement with an adsorption mechanism being the controlling step rate. This model is represented as equation (10) [39-41]:

$$
\mathrm{t} / \mathrm{qt}=1 / \mathrm{k}_{2} \mathrm{q}_{\mathrm{e}}^{2}+\left(1 / \mathrm{q}_{\mathrm{e}}\right) \mathrm{t}
$$

$\mathrm{k}_{2}\left(\mathrm{~g} \mathrm{mg}^{-1} \mathrm{~min}^{-1}\right)$ is the rate constant of PSORE and the constants can be determined experimentally by plotting of $\mathrm{t} / \mathrm{qt}$ against $\mathrm{t}$.

iii. Resistance to Intraparticle diffusion model (RIDE)

For systems controlled by the resistance to intraparticle diffusion complex models exist; however, a first diagnostic on the impact of this mechanism in the control of uptake kinetics can be obtained using a simplified Eq.(11):

$$
\mathrm{q}_{\mathrm{t}}=k_{\text {int }} \cdot \mathrm{t}^{0.5}+\mathrm{c}
$$

where $q_{\mathrm{t}}\left(\mathrm{mg} \mathrm{g}^{-1}\right)$ is the amount of metal ions adsorbed at time $\mathrm{t}(\mathrm{min})$, and $k_{\text {int }}\left(\mathrm{mg} \mathrm{g}^{-1} \min ^{-0.5}\right)$ is the intraparticle diffusion constant. According to Eq. (11), a plot of $\mathrm{q}_{\mathrm{t}} \sim \mathrm{t}^{0.5}$ should be a straight line with a slope $\mathrm{k}_{\text {int }}$ and intercept $\mathrm{c}$.

In the present study, experimental data have been fitted by the aforementioned kinetic models. The rate constants, calculated U(VI) equilibrium uptakes, and corresponding correlation coefficients were calculated and have been reported in Table 4 and shown in Figure 6. In the case of pseudo first order kinetic equation, the calculated sorption 
capacity value $\left(\mathrm{q}_{\mathrm{e}}\right.$ cal. $\left.=11.85 \mathrm{mg} \mathrm{g}^{-1}\right)$ significantly deviated from the experimental ones $\left(\mathrm{q}_{\mathrm{e}}\right.$ exp. $\left.=8.82 \mathrm{mg} \mathrm{g}^{-1}\right)$ and also the correlation coefficient was very low. While in pseudo second order the predicted $\mathrm{U}(\mathrm{VI})$ uptake $\left(\mathrm{q}_{\mathrm{e}}\right.$ cal. $=9.74 \mathrm{mg} \mathrm{g}^{-}$ $\left.{ }^{1}\right)$ was consistent with the experimental one. Additionally, the correlation coefficient for the pseudo second order kinetic equation $\left(\mathrm{R}^{2}=0.9911\right)$ was much higher than in the case of the pseudo first order $\left(\mathrm{R}^{2}=0.9864\right)$. The (RIDE) model show poor correlation coefficient $\left(\mathrm{R}^{2}=0.8462\right)$ if compared with the correlation coefficient of pseudo second-order model, this means that the (RIDE) model is not playing a significant role in the control of uptake kinetics and the pseudo-second order sorption mechanism is the predominant and the rate limiting step is the chemical sorption mechanism.

Table 4. Kinetics parameters for U(VI) ions sorption.

\begin{tabular}{llll}
\hline Model & Parameters & & \\
\hline Pseudo-first order rate equation (PFORE) & $\mathrm{K}_{1}$ & $\mathrm{q}_{\mathrm{e}}$ & $\mathrm{R}^{2}$ \\
& $9.8 \times 10^{-2} \mathrm{~min}^{-1}$ & $11.85 \mathrm{mg} \mathrm{g}^{-1}$ & 0.986 \\
& $\mathrm{~K}_{2}$ & $\mathrm{q}_{\mathrm{e}}$ & $\mathrm{R}^{2}$ \\
Pseudo-second order rate equation (PSORE) & $0.014 \mathrm{~g} \mathrm{mg}^{-1} \mathrm{~min}^{-1}$ & $9.74 \mathrm{mg} \mathrm{g}^{-1}$ & 0.991 \\
Resistance to intraparticle diffusion equation (RIDE) & $\mathrm{C}$ & $\mathrm{K}_{\text {int }}$ & $0.9843 \mathrm{mg} \mathrm{g}^{-1}$ min- \\
\hline
\end{tabular}
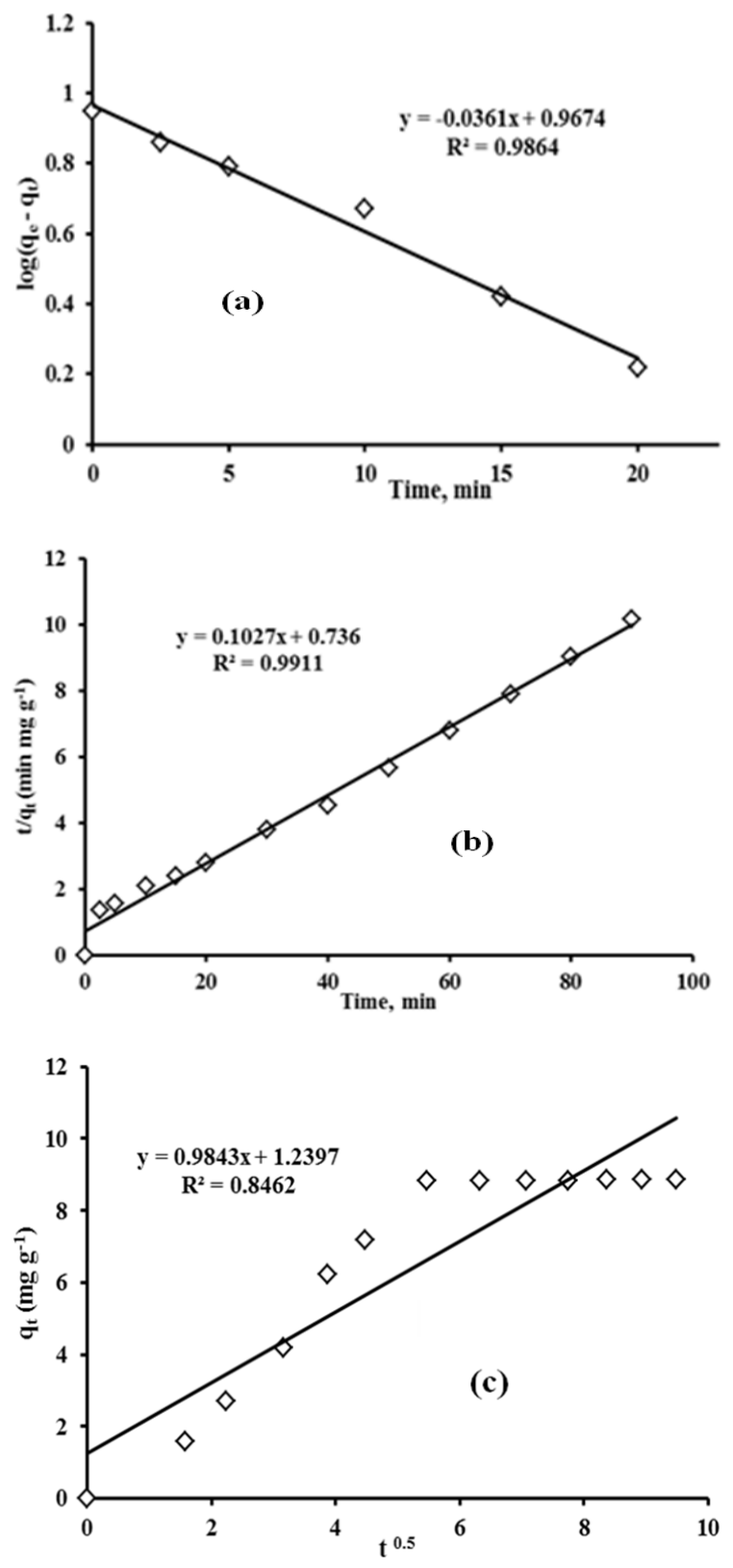

Figure 6. Kinetic models: (a) PFORE, (b) PSORE and (c) RIDE for U(VI) sorption onto Lewatit MonoPlus M500.

\subsection{Effect of Temperature on Sorption Process and Thermodynamic Parameters}

The temperature of the solution is an important parameter for the adsorption of $\mathrm{UO}_{2}{ }^{2+}$ ions; an increase or decrease in temperature will change the equilibrium capacity of the adsorbents during the process of adsorption. Also thermodynamic parameters are used to explain the mechanism of adsorption. The effect of temperature on uranium adsorption on the resin was studied at different temperature in the range $298 \mathrm{~K}$ to $343 \mathrm{~K}$. The sorption of uranyl ions decreases with increasing the temperature as shown in Figure 7.

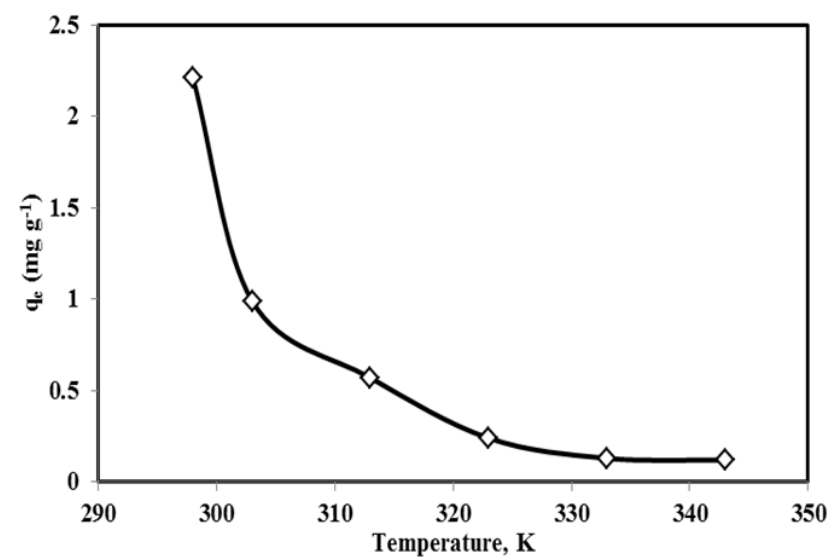

Figure 7. Effect of temperature on adsorption efficiency of Lewatit MonoPlus M500.

This decrease in the uranium uptake capacity with increasing temperature might be due to a decreasing effect on the surface activity where at high temperature, the thickness of the boundary layer would decrease due to the increasing tendency of U(VI) to escape to the solution phase [12].

The uranium adsorption at room temperature $(298 \mathrm{~K})$ reached $88.2 \%$ and decreased down to $4.64 \%$ at $343 \mathrm{~K}$ : the reaction is by exothermic nature. This is confirmed by the determination of the enthalpy change $\left(\Delta \mathrm{H}^{\circ}\right)$, the entropy change $\left(\Delta \mathrm{S}^{\circ}\right)$ and the Gibbs free energy $\left(\Delta \mathrm{G}^{\circ}\right)$ of the reaction which are reported in Table 5 and shown in Figure 8. 
Table 5. Thermodynamic parameters of $U(V I)$ ions sorption.

\begin{tabular}{|c|c|c|c|c|c|c|c|c|}
\hline \multirow{2}{*}{$\Delta \mathbf{H}^{\circ}\left(\mathrm{kJ} \mathrm{mol}^{-1}\right)$} & \multirow{2}{*}{$\Delta \mathrm{S}^{\circ}\left(\mathrm{J} \mathrm{K}^{-1} \mathrm{~mol}^{-1}\right)$} & \multicolumn{6}{|c|}{$\Delta \mathrm{G}^{\circ}\left(\mathrm{kJ} \mathrm{mol}^{-1}\right)$} & \multirow{2}{*}{$\mathbf{R}^{2}$} \\
\hline & & $298 K$ & 303K & 313K & $323 K$ & 333K & $343 K$ & \\
\hline-80.884 & -245.35 & -7.769 & -6.542 & -4.089 & -1.635 & 0.817 & 3.271 & 0.9099 \\
\hline
\end{tabular}

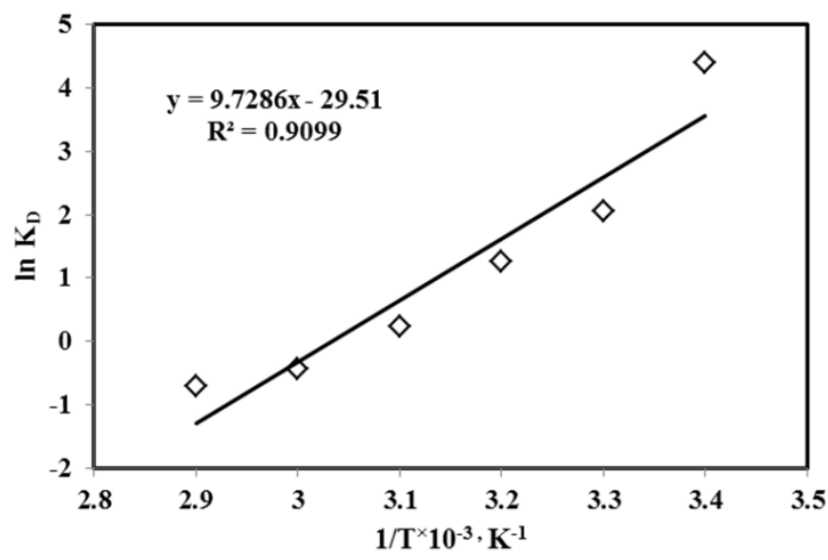

Figure 8. Van't Hoff plots of $\ln K_{D}$ against $1 / T$ for U(VI) ions sorption.

From Table 5, it is clear that $\Delta \mathrm{H}^{\circ}$ has negative value which confirms the exothermic nature of the sorption process. In addition, the negative $\Delta S^{\circ}$ value suggests decreasing the system randomness at the solid-liquid interface during the adsorption process. The negative value of $\Delta \mathrm{G}^{\circ}$ which decrease with increasing temperature indicates the spontaneous nature of the sorption process and it's more efficient at low temperature.

\section{FTIR Study for Both Free and Loaded Lewatit MonoPlus M500 with U(VI)}

FTIR spectroscopy was employed to confirm the interaction between Lewatit MonoPlus M500 resin and uranium ions. The spectra of resin before and after uranium adsorption were presented in Figure $9(\mathrm{a}, \mathrm{b})$. From the figure, it has been realized that some characteristic peaks representing the major groups of the studied resin have a sharp intensity that turned to medium intensity after the adsorption experiments. This indicates that the studied sorbant is able to form complex with $\mathrm{U}(\mathrm{VI})$ metal ions in the sulfate solution. Accordingly, the bands of various intensity occurring at $3423.99 \mathrm{~cm}^{-1}, 3020.94$ $\mathrm{cm}^{-1}$ and $2923.56 \mathrm{~cm}^{1-}$ associated with valence vibrations of a $\mathrm{C}-\mathrm{H}$ bond in an aromatic ring and the methylene group $\left(-\mathrm{CH}_{2}\right)$ in the polystyrene chain. The bands at about $1482.99 \mathrm{~cm}^{-1}$ as well as $1422.24 \mathrm{~cm}^{-1}$ assigned to scissoring vibration of the methylene group in the polystyrene chain, the bands at $1381.75 \mathrm{~cm}^{-1}$ corresponding to benzene ring vibration. The frequencies $1625.7 \mathrm{~cm}^{-1}$ and $830.2 \mathrm{~cm}^{-1}$ correspond to the skeleton aromatic stretching and bending vibrations respectively, of the alkene $\mathrm{C}=\mathrm{C}$ bonds in the ring plane [42].

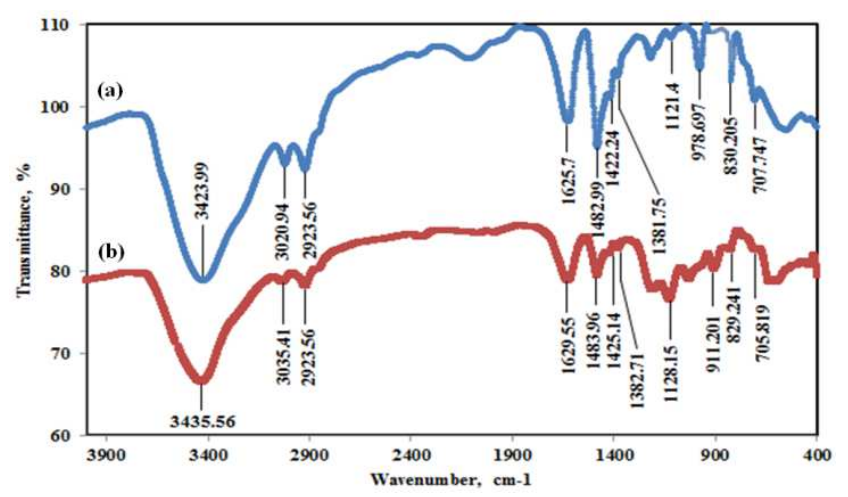

Figure 9. FTIR spectrum of Lewatit MonoPlus M500 before (a) and after (b) uranium loading.

On the other hand, there are characteristic bands at 1121 $\mathrm{cm}^{-1}$ and $707.74 \mathrm{~cm}^{-1}$ assigned to $\mathrm{C}-\mathrm{N}$ antisymmetric and symmetric stretch vibration absorption, respectively. In addition, the peaks related to the quaternary nitrogen appear at $978.68 \mathrm{~cm}^{-1}$ [9]. It is thus possible to mention that Lewatit MonoPlus M 500 resin exhibits, indeed, good affinity towards the U(VI) metal ions in sulphate solution. The FTIR showed new absorption bands which weren't assigned in the spectrum of Lewatit MonoPlus M 500 resin; a characteristic peak of $\mathrm{UO}_{2}{ }^{2+}$ has been clearly observed at $911.2 \mathrm{~cm}^{-1}$ [43- 48]. U(VI) metal ions have replaced the sulfate ions in the adsorption step and to be released by elution. It has also to be mentioned that, it is clearly evident that the formed complex between U (VI) metal ions and the resin would take place by the reaction of uranium metal ions and sulfate ions [49].

\section{Scanning Electron Microscope (SEM) for Both Free and Loaded Lewatit MonoPlus M500 with U(VI)}

The morphologies of Lewatit MonoPlus M500 resin before (a) and after (b) U(VI) uptake are presented in Figure 10 (a, b). As seen in Figure $10(a, b)$, the surface of resin before and after absorption was smooth, well-ordered and has a good uniformity, but after the adsorption the resin surface become more brilliant and brighter than before adsorption, this demonstrates that the sorption of U(VI) ions have taken place onto the resin, also the resin has the ability to resist the mechanical damage during experimental operation. 

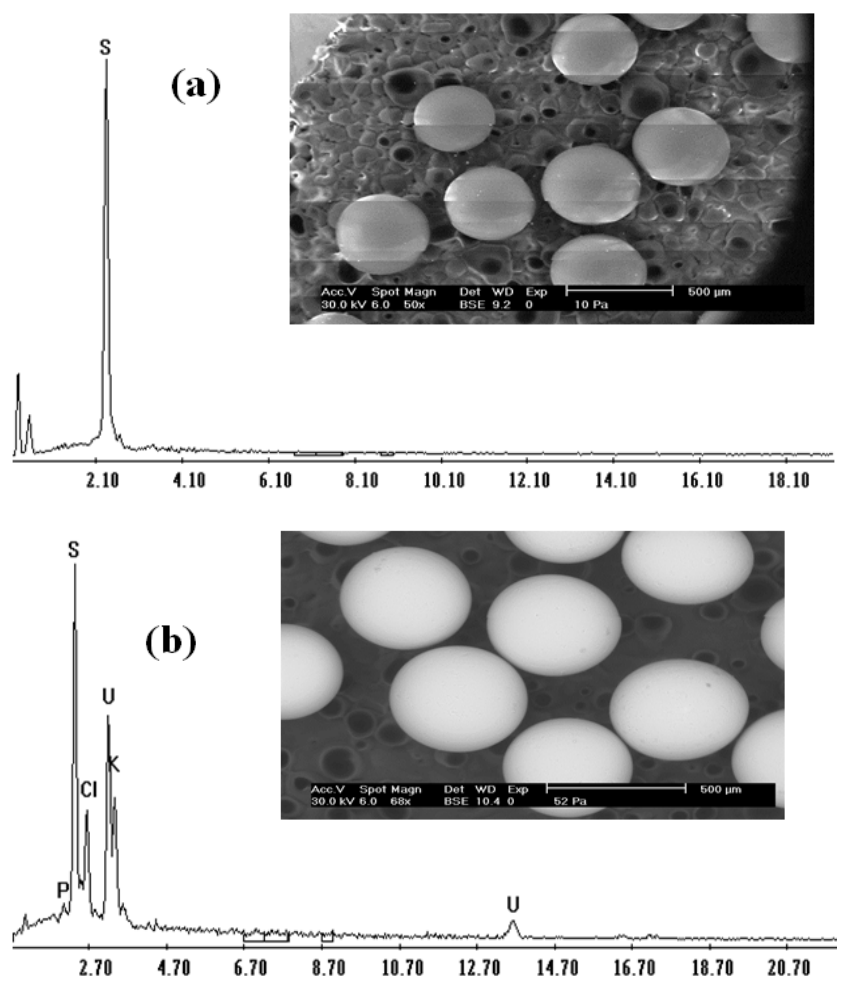

Figure 10. SEM images of Lewatit MonoPlus M500 before (a) and after (b) uranium loading.
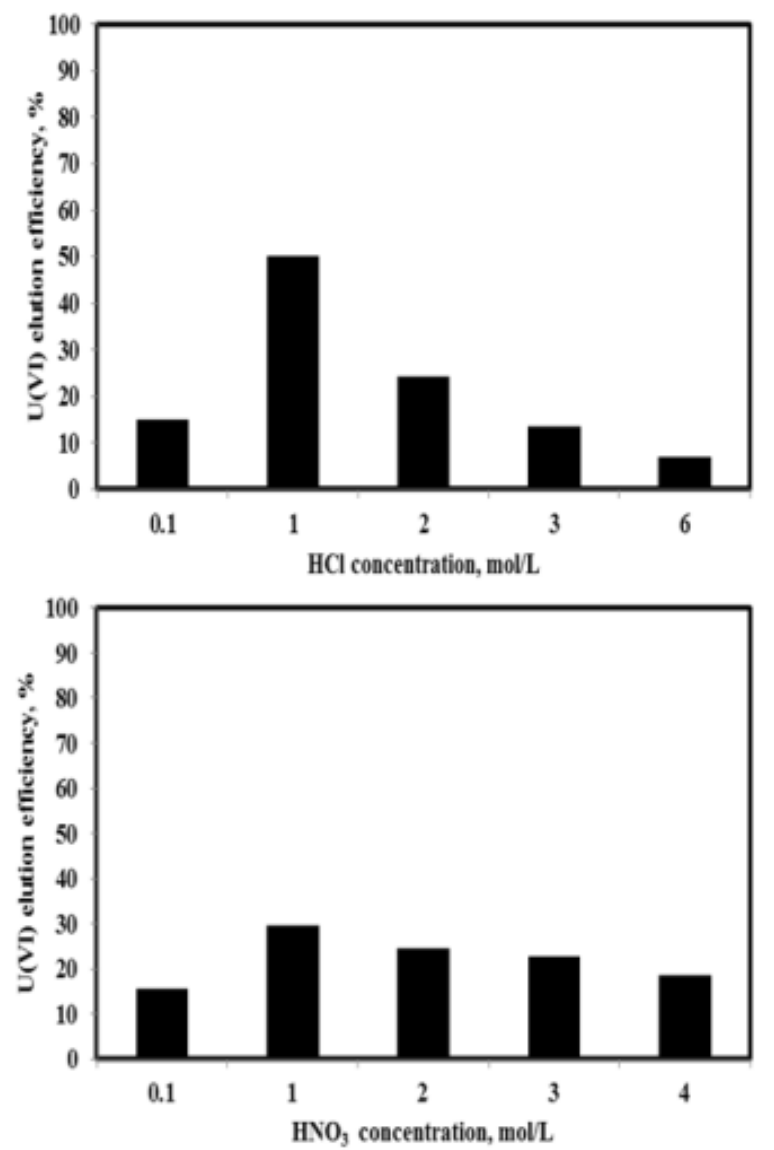

\section{Desorption Experiments and Reusability of Lewatit MonoPlus M500}

To enhance the economic value of the sorption process, desorption process was studied. The desorption process will help to regenerate the spent adsorbent so that it can again be reused to adsorb uranium. Also the mechanism of uranium uptake as well as reusability of adsorbent can be better understood via desorption experiments.

\subsection{Effect of the Eluting Agent type}

The desorption characteristics of uranyl ions were analyzed by making use of various eluents were equilibrated with different portions of the resin containing a maximum of adsorbed uranium. Several eluents were tested: acidic (0.1-6.0 $\mathrm{M} \mathrm{HCl}, 0.1-4.0 \mathrm{M} \mathrm{HNO}_{3}, 0.1-1.0 \mathrm{M} \mathrm{HCl}+0.1-1.0 \mathrm{M} \mathrm{HNO}_{3}$, 0.1-2 $\left.\mathrm{M} \mathrm{H}_{2} \mathrm{SO}_{4}\right)$, basic $\left(0.5-2.0 \mathrm{M} \mathrm{NH}_{4} \mathrm{OH}\right)$ and $(1.0 \mathrm{M} \mathrm{HCl}+$ $2.0 \mathrm{M} \mathrm{NaCl}, 0.5 \mathrm{M} \mathrm{HCl}+2.0 \mathrm{M} \mathrm{NaCl}, 0.25 \mathrm{M} \mathrm{HCl}+2.0 \mathrm{M}$ $\mathrm{NaCl}$ ) solutions. As can be seen from the presented data in the following Figure 11, the desorption efficiency of U(VI) from the Lewatit MonoPlus M500 is different depending on the eluting agents used. Also, $\mathrm{NH}_{4} \mathrm{OH}$ solution is not a suitable agent in $\mathrm{U}(\mathrm{VI})$ removal from loading resins. In this case desorption efficiency is nearly null. It was obvious that $(\mathrm{HCl} 1.0 \mathrm{M} / 2.0 \mathrm{M}$ $\mathrm{NaCl}$ ) has resulted in $99 \% \mathrm{U}(\mathrm{VI})$ elution efficiency.
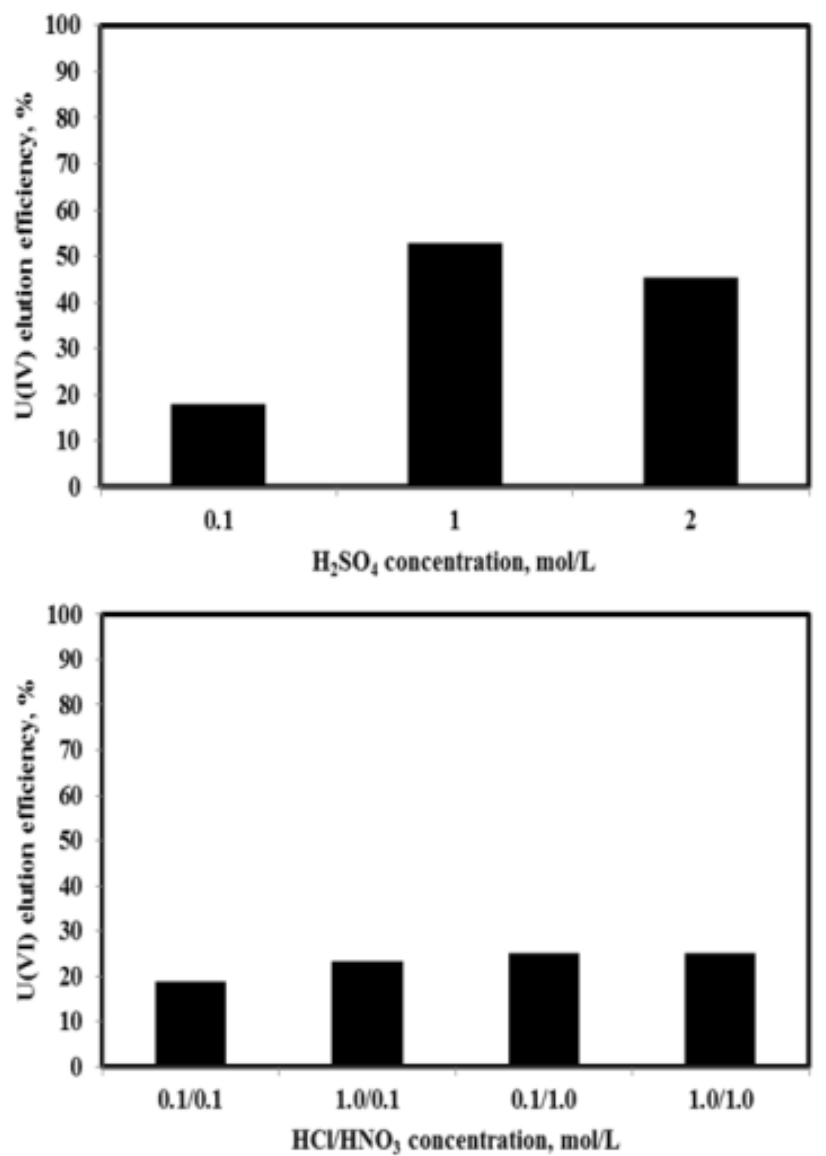


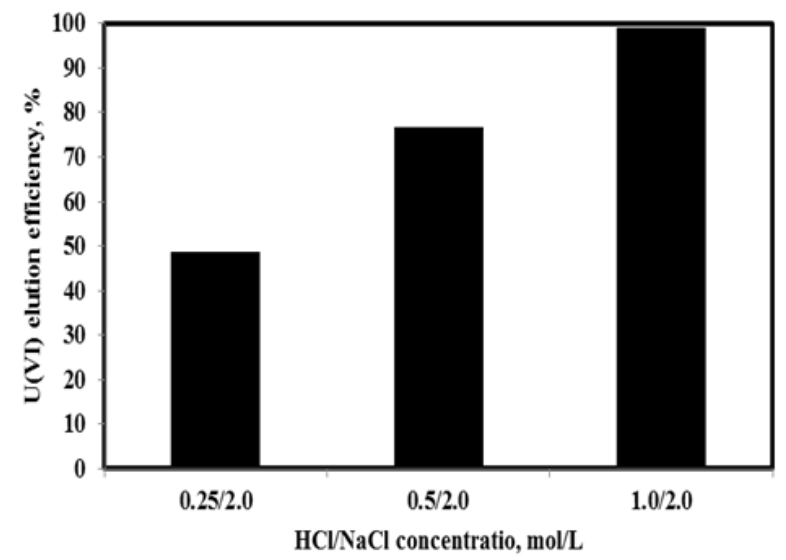

Figure 11. Elution possibility of U(VI) from Lewatit MonoPlus M500.

\subsection{Reusability of Lewatit MonoPlus M500}

To determine the reusability of the Lewatit MonoPlus resin M500, a repetitive adsorption-desorption cycles were achieved upon the same adsorbent dose using a fresh solution for each cycle under the optimum condition of adsorption and desorption. During the first $17^{\text {th }}$ cycle the adsorption and desorption of uranium have been realized, after that the adsorption efficiency of the resin has decreased from $90.6 \%$ to reach $85 \%$ in the 23th cycle. Also, the desorption efficiency decreased from $96 \%$ to $90 \%$ in the 23 th cycle. Therefore, the Lewatit MonoPlus M500 is a promising adsorbent that can be used to remove uranium in aqueous solution due to their high reusability and mechanical stability.

\section{Case Study}

In the present work, we are studying the possibility of upgrading uranium in the impure crude uranium concentrate of Gattar pilot plant, from Nuclear Material Authority, Egypt.

For the upgrading procedure suggested in the present work a proper 1L sulphate solution has been prepared by dissolution of $10 \mathrm{~g}$ of the crude concentrate in $30 \mathrm{~g} / 1$ sulpuric acid solution. During dissolution the gross amount of silica and other insoluble have been removed as insoluble residue which was then filtrated and washing until having 1 liter clear solution of the working crude uranium concentrate [50].

Table 6. Chemical analysis of the studied sample.

\begin{tabular}{llllll}
\hline Element & Wt. \% & Element & Wt. \% & Element & Wt.\% \\
\hline $\mathrm{U}$ & 35.8000 & $\mathrm{Fe}$ & 1.2234 & $\mathrm{Sr}$ & 0.0490 \\
$\mathrm{Ag}$ & 0.0668 & $\mathrm{~K}$ & 0.2612 & $\mathrm{~V}$ & $\mathrm{Zn}$ \\
$\mathrm{Al}$ & 0.0886 & $\mathrm{Mg}$ & 0.4377 & $\mathrm{Ce}$ & 0.0095 \\
$\mathrm{Ca}$ & 2.1222 & $\mathrm{Mn}$ & 0.0174 & $\mathrm{Sm}$ & 0.0202 \\
$\mathrm{Cd}$ & 0.0046 & $\mathrm{Na}$ & 4.2794 & $\mathrm{~Tb}$ & 0.6708 \\
$\mathrm{Co}$ & 0.0086 & $\mathrm{Ni}$ & 0.0266 & $\mathrm{Ho}$ & 0.1888 \\
$\mathrm{Cr}$ & 0.0094 & $\mathrm{P}$ & 0.0742 & $\mathrm{Tm}$ & 0.1080 \\
$\mathrm{Cs}$ & 0.0320 & $\mathrm{Si}$ & 0.0120 & & 0.1024 \\
$\mathrm{Cu}$ & 0.0164 & & & \\
\hline
\end{tabular}

The obtained clarified solution's $\mathrm{pH}$ was adjusted to be ready for sorption experiments. From the above giving, it was found greatly interesting to apply a suggested procedure for upgrading G. Gattar crude yellow cake via its proper treatment with Lewatit MonoPlus M500 resin.

Lewatit MonoPlus M500 resin has been tested for recovering uranium from impure crude uranium concentrate, the solution was adjusted to $\mathrm{pH}=1.8$; contact time $30 \mathrm{~min}$; resin-liquid ratio $(\mathrm{R} / \mathrm{L}) \quad 1: 50$ and agitation rate $200 \mathrm{rpm}$ at room temperature. By calculating the accumulated loaded uranium and comparing the loading capacity $(176.4 \mathrm{mg} \mathrm{U} / \mathrm{g}$ resin) with the obtained theoretical capacity $(181.82 \mathrm{mg} \mathrm{U} / \mathrm{g}$ resin), the loading capacity of a uranium study solution decreased from $90.6 \%$ to $88.2 \%$ may be due to the competition between uranium and different ions in the studied sample.

The working sample of Lewatit MonoPlus M500 resin loaded with uranium has been eluted effectively by using $(\mathrm{HCl}, 1.0 \mathrm{M} / 2.0 \mathrm{M} \mathrm{NaCl})$ solution at room temperature for 30 min contact time. The desorption efficiency of uranium was $99 \%$.

\section{Precipitation of Uranium(VI)}

Uranium was precipitated from the eluting solution by two ways using a) $25 \%$ ammonium hydroxide and b) hydrogen peroxide, respectively.

i) Precipitation by ammonium hydroxide

Uranium was precipitated as ammonium diuranate at $\mathrm{pH}$ 7.5 by drop-wise addition of $25 \%$ ammonium hydroxide on two cycles, the first cycle the purity of ammonium diuranate was $69.68 \%$, but in the second one the purity was increased to reach about $94.81 \%$ and assaying up to $71.19 \% \mathrm{U}$ has been obtained. The uranium precipitate was dried at $110^{\circ} \mathrm{C}$ and analysed for U(VI) using the Scanning Electron Microscope (SEM) for its elemental analysis as shown in Figure 12(a, b). 

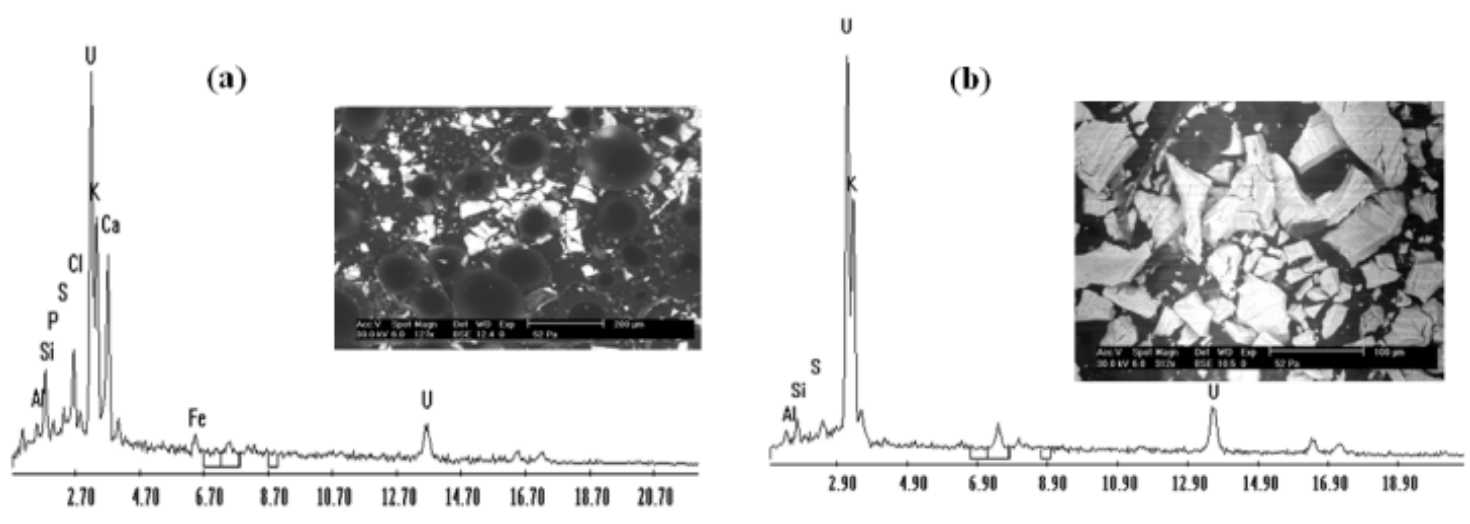

Figure 12. U(VI) precipitation by $\mathrm{NH}_{4} \mathrm{OH}$ (a) first cycle, (b) second cycle.

ii) Precipitation by hydrogen peroxide

Uranium precipitated from acidic solutions with hydrogen peroxide as shown in the following equation:

$$
\mathrm{UO}_{2}{ }^{2+}+\mathrm{H}_{2} \mathrm{O}_{2}+2 \mathrm{H}_{2} \mathrm{O} \rightarrow \mathrm{UO}_{4} \cdot 2 \mathrm{H}_{2} \mathrm{O}+2 \mathrm{H}^{+}
$$

The precipitate was dried at $110-120^{\circ} \mathrm{C}$ for $48 \mathrm{~h}$ and the SEM analysis for uranium product was has a purity of $94.67 \%$ from the first cycle as shown in Figure 13 and assaying up to $71 \% \mathrm{U}$ has been obtained.

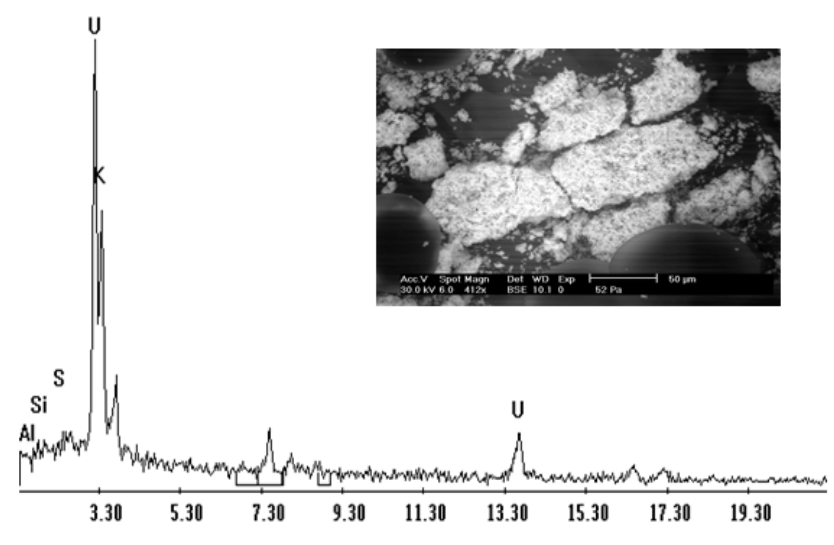

Figure 13. $U(V I)$ precipitation by $\mathrm{H}_{2} \mathrm{O}_{2}$.

\section{Conclusion}

The attained results of the present work revealed that Lewatit MonoPlus M500 adsorbent could be used effectively for uranium adsorption and removal from the studied crude yellow cake acidic solution. In this study, the batch experiments method were performed to optimize the $\mathrm{U}(\mathrm{VI})$ sorption under various conditions, including $\mathrm{pH}, \mathrm{U}$ (VI) initial concentration, contact time and temperature. The study on equilibrium sorption revealed that Langmuir isotherm model fits well to the experimental data confirming the monolayer adsorption of $\mathrm{U}(\mathrm{V})$ onto Lewatit MonoPlus M500 resin with maximum sorption capacity $\mathrm{q}_{\max } 181.82 \mathrm{mg} \mathrm{g}^{-1}$. Thermodynamic studies of the adsorption reaction of U(VI) with Lewatit MonoPlus M500 showed that the $\Delta \mathrm{H}^{\circ}$ of reaction equal to $\left(-80.884 \mathrm{~kJ} \mathrm{~mol}^{-1}\right)$. The negative value of $\Delta \mathrm{H}^{\circ}$ indicates that the adsorption is an exothermic process, with a decrease in the randomness of the system shown by negative value of entropy change $\Delta \mathrm{S}^{\circ}\left(-245.35 \mathrm{~J} \mathrm{~K}^{-1} \mathrm{~mol}^{-1}\right)$. The negative value of $\Delta \mathrm{G}^{\circ}$ indicates that the adsorption process was spontaneous. A kinetic study showed that the adsorption process was reached to equilibrium within $30 \mathrm{~min}$. The kinetic date fit well to pseudo-second order kinetic model which was more favorable as the predominant mechanism. Finally, the purity of uranium(VI) product from sulphate solution was $94.81 \%$ and $94.67 \%$ when using $\mathrm{NH}_{4} \mathrm{OH}$ and $\mathrm{H}_{2} \mathrm{O}_{2}$ solutions, respectively. It has been shown that uranium can be removed from solution and recovered by using a system which can be applied multiple times. Therefore, it has potential application in large scale.

\section{References}

[1] https://www.obermeier.de/en/products/ion-exchanger/.

[2] A. V. Zhizhin, I. N. Zakolodnyi, A. A. Zmitrodan, S. N. Orlov, Yu. V. Tsapko, A. V. Luzakov, D. S. Urtenov, G. P. Shovikov, K. A. Vagin, Results of Studies and Life Tests of RussianMade Monodisperse Nuclear-Grade Ion-Exchange Resins, Atomic Energy, 126 (2019) 96-102.

[3] F. J. Alguacil, E. Escudero, Removal of arsenic (V) from aqueous wastes by ion exchange with Lewatit MP64 resin, Desalination and water treatment, 261 (2018) 133-257.

[4] Bayer. Report: Efficiency Is a Matter of Form. http://www.lewatit.co.kr.

[5] N. B. Issa, V. N. Rajaković-Ognjanović, B. M. Jovanović, L. V. Rajaković, Separation and determination of arsenic species in water by selective exchange and hybrid resins, Analytica Chimica Acta, 673 (2010) 185-193.

[6] D. Kołodyńska, H. Hubicka, Z. Hubicki, Studies of application of monodisperse anion exchangers in sorption of heavy metal complexes with IDS, Desalination, 239 (2009) 216-228.

[7] A. N. Nikoloski, K. Ang, D. Li, Recovery of platinum, palladium and rhodium from acidic chloride leach solution using ion exchange resins, Hydrometallurgy, 152 (2015) 2032 .

[8] L. Rafati, A. H. Mahvi, A. R. Asgari, S. S. Hosseini, Removal of chromium (VI) from aqueous solutions using Lewatit FO36 nano ion exchange resin, Int. J. Environ. Sci. Tech., 7 (2010) $147-156$. 
[9] A. Wołowicz, Z. Hubicki, The use of the chelating resin of a new generation Lewatit MonoPlus TP-220 with the bispicolylamine functional groups in the removal of selected metal ions from acidic solutions, Chem. Eng. J., 197 (2012) 493-508.

[10] A. Wołowicz, Z. Hubicki, Ion Exchange Recovery of Palladium (II) from Acidic Solutions Using Monodisperse Lewatit SR-7, Ind. Eng. Chem. Res., 51 (2012) 16688-16696.

[11] S. Y. Afifi, M. M. Abo-Aly, S. M. Elashry, Alkaline Leaching for Recovery of Uranium and Copper from Calcareous Shale, Um Bogma formation, G. Allouga, Southwestern Sinai, Egypt, Arab J. Nucl. Sci. Appl, 50 (2017) 213-228.

[12] A. H. Orabi, K. A. Rabia, E. E. Elshereafy, A. R. Salem, Application of Commercial Adsorbent for Rare earth elements - Uranium Mutual Separation and Purification, Mediterr. J. Chem., 6 (2018) 238-254.

[13] Z. Marczenko, M. Balcerzak, Separation, preconcentration and spectrophotometry in inorganic analysis. Elsevier Science B. V., Amsterdam, (2000) p 521.

[14] W. Davies, W. Gray, A rapid and specific volumetric method for the precise determination of uranium using ferrous sulfate as a reductant, Talanta, 11 (1964) 1203-1211.

[15] G. Crini, H. N. Peindy, F. Gimbert, C. Robert, Removal of C. I. Basic Green 4 (Malachite Green) from aqueous solutions by adsorption processes using batch studies, Sep. Purif. Technol., 53 (2007) 97-110.

[16] A. Mellah, S. Chegrouche, M. Barkat, The removal of uranium (VI) from aqueous solutions onto activated carbon: Kinetic and thermodynamic investigations, J. Colloid. Interface Sci., 296 (2006) 434-441.

[17] S. M. Ghoreishi, M. Behpour, S. Mazaheri, Motaghedifard High sensitive sensorbased on carbon nanotube electrode for determination of lanthanum in the presence of calcon carboxylic acid, Anal. Lett. 46 (2013) 156-170.

[18] F. Nachod, J. Schubert, Ion Exchange Technolgy, Academic Press Inc. Publishers New York, (1956).

[19] G. Sheng, J. Sheng, S. Yang, J. Hu, X. Wang, Behavior and mechanism of Ni (II) uptake on $\mathrm{MnO}_{4}$ by a combination of macroscopic and EXAFS investigation, J Radioanal. Nucl. Chem., 289 (2011) 129-135.

[20] H. Yan, L. Yang, Z. Yang, H. Yang, A. Li, R. Cheng., Preparation of chitosan/poly (acrylic acid) magnetic composite microspheres and applications in the removal of copper (II) ions from aqueous solutions, J. Hazard. Mater., 371 (2012) 229-230.

[21] N. Li, R. B. Bai, Copper adsorption on chitosan-cellulose hydrogel beads: behaviors and mechanisms, Sep. Purif. Technol., 42 (2005) 237-247.

[22] I. Langmuir, The adsorption of gases on plane surfaces of glass, mica and platinum, J. Amer. Chem. Soc., 40 (1918) 1361-1403.

[23] K. Y. Foo, B. H. Hameed, Insights into the modeling of adsorption isotherm systems, Chem. Eng. J., 156 (2010) 2-10.

[24] K. Bharathi, S. Ramesh, Removal of dyes using agricultural waste as low-cost adsorbents: a review, Appl. Water Sci., 3 (2013) 773-790.
[25] S. Lagergren, About the Theory of So-Called Adsorption of Soluble Substances, Kungliga Svenska Vetenskapsakademiens Handlingar, 24 (1898) 1-39.

[26] H. M. F. Freundlich, U“ ber die adsorption in lo"sungen, Z. Phys. Chem., 57 (1906) 385-470.

[27] E. Voudrias, F. Fytianos and E. Bozani, Sorption Description isotherms of Dyes from aqueous solutions and Waste Waters with Different Sorbent materials, Global Nest, The Int. J., 4 (2002) 75-83.

[28] S. Mohan, and J. Karthikeyan, Removal of lignin and tannin color from aqueous solution by adsorption onto activated carbon solution by adsorption onto activated charcoal, Environ. Pollut., 97, (1997) 183-187.

[29] A. Gunay, E. Arslankaya, I. Tosun, Lead removal from aqueous solution by natural and pretreated clinoptilolite: adsorption equilibrium and kinetics, J. Hazard. Mater., 146 (2007) 362-371.

[30] A. Dabrowski, Adsorption-from theory to practice, Adv. Colloid Interface Sci., 93 (2001) 135-224.

[31] M. M. Dubinin, The potential theory of adsorption of gases and vapors for adsorbents with energetically non-uniform surface, Chem. Rev., 60 (1960) 235-266.

[32] J. P. Hobson, Physical adsorption isotherms extending from ultra-high vacuum to vapor pressure, J. Phys. Chem., 73 (1969) 2720-2727.

[33] J. Xu, M. Chen, C. Zhang, Z. Yi, Adsorption of uranium (VI) from aqueous solution by diethylenetriamine-functionalized magnetic chitosan, J. Radioanal. Nucl., Chem. 298 (2013) 1375-1383.

[34] H. M. F. Freundlich, Over the Adsorption in Solution, J. Phys. Chem. 57 (1906) 385-471.

[35] A. Rahmati, A. Ghaemi, M. Samadfam, Kinetic and thermodynamic studies of uranium (VI) adsorption using Amberlite IRA-910 resin, Annals of Nuclear Energy, 39 (2012) 42-48.

[36] M. F. Cheira, B. M. Atia, M. N. Kouraim, Uranium (VI) recovery from acidic leach liquor by Ambersep 920U $\mathrm{SO}_{4}$ resin: Kinetic, equilibrium and thermodynamic studies, Journal of Radiation Research and Applied Sciences, 10 (2017) 307-319.

[37] Y. M. Khawassek, A. M. Masoud, M. H. Taha, A. E. M. Hussein, Kinetics and thermodynamics of uranium ion adsorption from waste solution using Amberjet $1200 \mathrm{H}$ as cation exchanger, J. Radioanal. Nucl. Chem., 315 (2018) 493-502.

[38] N. Reynier, R. Lastra, C. Laviolette, J. Fiset, N. Bouzoubaâ, M. Chapmanb, Uranium Recovery by Ion Exchange from Sulfuric Acid Liquor in Iodide and Chloride Media, Solvent Extraction and Ion Exchange, 34 (2016) 188-200.

[39] H. Qiu, L. Lv, B. Pan, Q. Zhang, W. Zhang, Q. Zhang, Critical review in adsorption kinetic models, J. Zhejiang Univ. Sci. A, 10 (2009) 716-724.

[40] S. Yiacoumi, C. Tien. Kinetics of metal ion adsorption from aqueous solutions: Models, Algorithms, and Applications. Kluwer Academic publishers. USA (1995).

[41] Y. S. Ho, Review of second-order models for adsorption systems, J. Hazard. Mater., 136 (2006) 681-689. 
[42] J. Jachuła, D. Kołodyńska, Z. Hubicki, Sorption of $\mathrm{Cu}(\mathrm{II})$ and $\mathrm{Ni}(\mathrm{II})$ ions in the presence of the methylglycinediacetic acid by microporous ion exchangers and sorbents from aqueous solutions, Cent. Eur. J. Chem., 9 (2011) 52-65.

[43] S. Choi, Y. C. Nho, Adsorption of $\mathrm{UO}^{2+}{ }_{2}$ by polyethylene adsorbents with amidoxime, carboxyl, and amidoxime/carboxyl group, Radiation Physics and Chemistry, 57 (2000) 187-193.

[44] C. R. Preetha, J. M. Gladis, T. P. Rao, G. Venkateswaran, Removal of toxic uranium from synthetic nuclear power reactor effluents using uranyl ion imprinted polymer particles, Environmental Science and Technology, 40 (2006) 3070-3074.

[45] D. James, G. Venkateswaran, T. P. Rao, Removal of uranium from mining industry feed simulant solutions using trapped amidoxime functionality within a mesoporous imprinted polymer material, Microporous mesoporous materials, 119 (2009) 165-170.

[46] A. M. Shallaby, M. M. Mostafa, K. M. Ibrahim, M. N. H. Moussa, New uranyl (VI) complexes with hydrazine-oximes derived from aromatic acid hydrazides and biacetylmonoxime-1, Spectro chimica Acta Part A: Molecular Spectroscopy, 40 (1984) 999-1002.

[47] M. F. Hasan, A. M. Seyam, H. A. Hodali, Some dioxouranium (VI) complexes of azo-oximes, Polyhedron, 11 (1992) 17331736.

[48] A. Yacoutanour, A. K. T. Maki, M. M. Mostafa, Synthesis and spectroscopic studies of dioxouranium (VI) complexes derived from some oximes and containing dihydroxo bridges, Spectro chimica Acta, 44A (1988) 1291-1296.

[49] G. M. Hussein, S. S. Muhammad, N. A. Gomaa, M. R. Shehata, W. M. Hosny, Potentiality of methyltrioctylammonium chloride ligand for selective extraction of the Uranium (VI) metal ions from selective carbonate leach liquor, J, Dis. Sci. Tec., 38 (2017) 1204-1210.

[50] M. F. Cheira, R. A. Ghazala, K. F. Mahmoud, An upgrading procedure for the uranium concentrate product of Gattar pilot plant via ammonium carbonate, Inorganic Chemistry An Indian Journal, 8 (2013) 61-68. 